\title{
CD20 monoclonal antibody targeted nanoscale drug delivery system for doxorubicin chemotherapy: an in vitro study of cell lysis of CD20-positive Raji cells
}

\author{
This article was published in the following Dove Press journal: \\ International Journal of Nanomedicine \\ 2 November 2016 \\ Number of times this article has been viewed
}

\begin{abstract}
Shuang Jiang, ${ }^{1,2, *}$ Xiaobo Wang, ${ }^{2, *}$ Zhiran Zhang, ${ }^{2}$ Lan Sun, ${ }^{3}$ Yunzhu $\mathrm{Pu},{ }^{3}$ Hongjuan Yao, ${ }^{3}$ Jingcao $\mathrm{Li}^{3}{ }^{3}$ Yan Liu, ${ }^{3}$ Yingge Zhang, ${ }^{3}$ Weijing Zhang ${ }^{1,4}$

'Department of Lymphoma, Affiliated Hospital of the Military Medical Academy of Sciences, Beijing, 'Department of Pharmacy, 210th Hospital of the People's Liberation Army, Dalian, ${ }^{3}$ Key Laboratory of Nanopharmacology and Nanotoxicology, Institute of Pharmacology and Toxicology, Academy of Military Medical Sciences, ${ }^{4}$ Department of Lymphoma, Beijing Shijitan Hospital of Capital Medical University, Beijing, People's Republic of China

*These authors contributed equally to this work
\end{abstract}

Correspondence: Yingge Zhang Institute of Pharmacology and Toxicology, Academy of Military Medical Sciences, Room 2255, North Building, 27 Taiping Road, Haidian District, Beijing 100850,

People's Republic of China

Tel +861066930654

$\mathrm{Fax}+86 \quad 106821 \quad 1656$

Email zhangyg58@।26.com

Weijing Zhang

Department of Lymphoma, Affiliated Hospital of the Military Medical Academy of Sciences, 8th Street East, Fengtai District, Beijing 10007I, People's

Republic of China

Tel +86 I0 63926950

Email zhangwj3072@I63.com

\begin{abstract}
A monoclonal antibody targeted nanoscale drug delivery system (NDDS) for chemotherapy was evaluated in CD20-positive Raji cells in vitro. Nanoparticles were formed by the assembly of an amphiphilic polymer consisting of 1,2-distearoyl-sn-glycero-3-phosphoethanolamine-N-methoxypolyethyleneglycol-2000 (DSPE-PEG2000). Active carbon nanoparticles (ACNP) were conjugated to the chemotherapeutic agent, doxorubicin (DOX), and the nanoliposome carrier, DSPE-PEG2000 and DSPE-PEG2000- $\mathrm{NH}_{2}$ conjugated to the human anti-CD20 monoclonal antibody that targets B-lymphocytes. This monoclonal antibody targeted nanoparticle delivery system for chemotherapy formed the active NDDS complex, ACNP-DOX-DSPEPEG2000-anti-CD20. This active NDDS was spherical in morphology and had good dispersion in the culture medium. When compared with the effects on CD20-negative YTS cells derived from natural killer/T-cell lymphoma, the active NDDS, ACNP-DOX-DSPE-PEG2000-antiCD20, demonstrated DOX delivery to CD20-positive Raji cells derived from Burkitt's lymphoma (B cell lymphoma), resulting in increased cell killing in vitro. The intracellular targeting efficiency of the ACNP-DOX-DSPE-PEG2000-anti-CD20 complex was assessed by confocal laser microscopy and flow cytometry. The findings of this in vitro study have shown that the DSPE-PEG2000 polymeric liposome is an effective nanocarrier of both a monoclonal antibody and a chemotherapy agent and can be used to target chemotherapy to specific cells, in this case to CD20-positive B-cells. Future developments in this form of targeted therapy will depend on the development of monoclonal antibodies that are specific for malignant cells, including antibodies that can distinguish between lymphoma cells and normal lymphocyte subsets.
\end{abstract}

Keywords: CD20, active carbon nanoparticles, doxorubicin, nanoscale drug delivery, targeted therapy, DSPE-NH2-anti-CD20 conjugate

\section{Introduction}

Non-Hodgkin's lymphoma (NHL) is currently classified into high- and low-grade, B- and T-cell lymphomas and accounts for at least $90 \%$ of the cases of lymphoma, with Hodgkin's lymphoma and other forms of lymphoma representing the remaining $10 \%$ of cases. B-cell NHL is the most common type of NHL, accounting for $85 \%$ of cases in People's Republic of China. ${ }^{1}$ Patients with high-grade, B-cell NHL may require treatment with high-dose chemotherapy and immunotherapy using monoclonal antibodies. ${ }^{2} \mathrm{New}$ treatments for high-grade B-cell NHL now include liposomal doxorubicin (DOX), ${ }^{3}$ the anti-CD20 monoclonal antibody Rituximab, ${ }^{4}$ the CD20 monoclonal antibody-conjugated isotope Zevalin, ${ }^{5}$ and proteasome inhibitors including bortezomib, ${ }^{6}$ which have improved 
the treatment of B-cell NHL. However, statistics show that the 5-year survival rate of high-grade B-cell NHL, including diffuse large cell B-cell lymphoma, is $<50 \%$. $^{7}$ Because these current forms of treatment options may have limited efficacy when used separately, it is possible that synergistic therapeutic effects will be obtained using the combination of chemotherapeutic and immunotherapeutic agents when they are delivered simultaneously to treat malignant lymphoma. Also, because systemic chemotherapy is toxic to normally proliferating cell populations, there is a need to develop more specific tumortargeting drugs to reduce treatment toxicities.

In targeting therapy, nanoparticles have unique advantages..$^{8-12}$ The enhanced permeability and retention effect is the theoretical foundation of tissue targeting of nanoparticle delivery systems. Nanoscale drug delivery systems (NDDS) have shown physical, chemical, pharmacokinetic, and pharmacodynamics properties, which give them advantages when compared with conventional pharmaceutical preparations in the treatment of malignant tumors. ${ }^{13-15}$

Active carbon nanoparticles (ACNP) have been used as an indicator of lymphatic circulation ${ }^{16}$ and act as a sustainedrelease drug delivery carrier ${ }^{17,18}$ with low toxicity ${ }^{19,20}$ and a large drug loading (DL) capacity due to their graphene composition. ${ }^{21-23}$ ACNP have been shown to have a constant rate of drug delivery and long drug half-life with effective drug delivery to their target tissues, especially to lymphatic tissues. ${ }^{24-29}$ However, ACNP preparations have poor water solubility and dispersion. Carbon nanoparticles can be coated with functional phospholipids, including amphiphilic polymers consisting of 1,2-distearoylsn-glycero-3-phosphoethanolamine-N-methoxypolyethylene glycol-2000 (DSPE-PEG2000), which improve the water solubility and stability of ACNP preparations. When components of DSPE-PEG2000 are replaced with DSPE-PEG2000$\mathrm{NH}_{2}$, the $-\mathrm{NH}_{2}$ molecule will react with the $-\mathrm{COOH}$ molecule of antibodies to form DSPE-PEG-antibody conjugates.

Studies of protein/antibody and therapeutic agents cotransported by nanoparticles for targeting therapy have made a lot of progress. ${ }^{30-32}$ The antibodies that are used in NDDS can target antigens on the cell surface, the effects of ACNP that carry chemotherapeutic drugs, and the stability of nanoparticles modified with PEG2000 have the potential to be used as targeted therapy in vivo to achieve active and passive targeted lysis of tumor cells.

Because of these recent developments, the present study was undertaken using a monoclonal antibody targeted NDDS for chemotherapy in CD20-positive Raji cells in vitro. Nanoparticles were formed by the assembly ofDSPE-PEG2000, with ACNP conjugated to the chemotherapeutic agent,
DOX, and the nanoliposome carrier DSPE-PEG2000, and DSPE-PEG2000- $\mathrm{NH}_{2}$ conjugated to the human anti-CD20 monoclonal antibody that targets B-lymphocytes.

\section{Materials and methods Materials}

ACNP (200 nm) were obtained from the Shanghai Hainuo Carbon Industry Co., (Shanghai, People's Republic of China). The zeta potential of the ACNP $(-49.8 \pm 1.50 \mathrm{mV})$ was detected with the Zetasize 3000 HS Laser Particle Size and Zeta Potential Analyzer (Malvern Instruments Ltd, Malvern, UK). The content of $\mathrm{C}$ was $97.58 \%$, $\mathrm{H}$ was $0.05 \%$, and $\mathrm{O}$ was $0.12 \%$. Recombinant anti-CD20 chimeric monoclonal antibody (anti-CD20 antibody) and fluorescein isothiocyanate (FITC)-conjugated recombinant anti-CD20 chimeric monoclonal antibody (FITC-CD20 antibody) were provided by Shanghai Zhangjiang Biotechnology Co. Ltd (Shanghai, People's Republic of China). DSPE-PEG2000 and 1,2-distearoyl-sn-glycero-3-phosphoethanolamine$\mathrm{N}$-amino-polyethylene glycol-2000 (DSPE-PEG2000-NH ${ }_{2}$ ) were purchased from the Shanghai Advanced Vehicle Technology Co. Ltd (Shanghai, People's Republic of China). DOX hydrochloride $(\mathrm{DOX} \cdot \mathrm{HCl})$ was purchased from Kainuochuntian Biotech (Beijing, People's Republic of China). 1-ethyl-3-(3-dimethylaminopropyl) carbodiimide $(\mathrm{EDC} \cdot \mathrm{HCl})$ and $\mathrm{N}$-hydroxysuccinimide (NHS) were purchased from Shanghai Medpep Co. Ltd (Shanghai, People's Republic of China). Hoechst 33258 and 4',6-diamidino-2phenylindole nuclear staining solution were purchased from Beyotime Biotechnology (Shanghai, People's Republic of China). The cell proliferation kit (MTT) and colorimetric cell viability assay kits were provided by Beijing CellChip Biotechnology Co., Ltd (Beijing, People's Republic of China).

\section{Methods}

\section{Construction and preparation of ACNP as drug carrier systems \\ Purification of ACNPs}

Initially, $3 \mathrm{~g}$ of commercially available ACNPs $(200 \mathrm{~nm})$ were suspended in sterile distilled water $(2 \mathrm{~L})$, and the mixed ACNP suspension was precipitated at room temperature for 72 hours. The supernatant was collected and filtered successively with 0.25 and $0.1 \mu \mathrm{m}$ microporous membranes, and ACNPs with a particle size of 100-150 nm were obtained. The purified ACNPs were lyophilized and stored at $-20^{\circ} \mathrm{C}$.

\section{Preparation of ACNP-DOX}

Purified ACNPs $100 \mathrm{mg}$ were activated at $100^{\circ} \mathrm{C}$ for 2 hours and suspended in triple-distilled water. Then, $50 \mathrm{mg}$ of DOX 
were added to the ACNP suspension using magnetic stirring for 30 minutes at room temperature in phosphate-buffered saline (PBS), pH 7.4. The solution was bathed in ice in an intermittent ultrasound field for 4 hours. The suspension was centrifuged at 16,000 rpm for 20 minutes. The ACNP-DOX precipitates were collected, resuspended, and centrifuged to remove unbound DOX. The supernatants were collected, and the DOX concentration was measured in an ultraviolet (UV) spectrometer. The DL coefficient and the encapsulation efficiency were calculated from the DOX concentration in the supernatant, using formulae (1) and (2), as given below. ${ }^{33}$ The ACNP-DOX was freeze-dried and stored at $-20^{\circ} \mathrm{C}$ until required for further use.

$$
\begin{aligned}
& \text { Weight of (feeding drug - }
\end{aligned}
$$

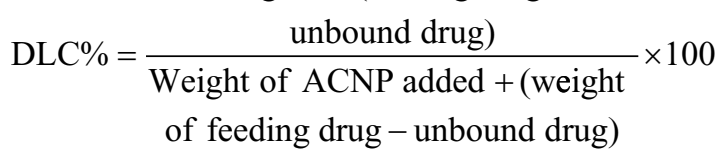$$
\mathrm{EE} \%=\frac{\begin{array}{c}
\text { Weight of (feeding drug }- \\
\text { unbound drug) }
\end{array}}{\text { Weight of feeding drug }} \times 100
$$

\section{Preparation of ACNP and ACNP-DOX coated with functionalized phospholipid}

DSPE-PEG2000 and DSPE-PEG2000- $\mathrm{NH}_{2}(5: 1, \mathrm{w} / \mathrm{w})$ were mixed and dissolved in organic solvent (chloroform: methanol =4:1 v/v). The prepared ACNP-DOX/ACNP was added to the DSPE-PEG2000 organic solution and mixed ultrasonically (DSPE-PEG2000:DSPE-PEG2000-NH : ACNP/ACNP-DOX =5:1:2). The organic solvent was evaporated using a rotary evaporator at $30^{\circ} \mathrm{C}$. Following evaporation, the walls of the container were lined by the phospholipid complex. The ACNP-DOX-DSPE-PEG2000$\mathrm{NH}_{2}$ was redispersed in PBS using ultrasonic mixing. The final concentration of ACNP-DOX in ACNP-DOX-DSPEPEG2000- $\mathrm{NH}_{2}$ was $1 \mathrm{mg} / \mathrm{mL}$, and the corresponding final concentration of DOX was $250 \mu \mathrm{g} / \mathrm{mL}$.

\section{Preparation of the NDDS, ACNP-DOX-DSPE-PEG2000- anti-CD20 (Figure I)}

For the covalent attachment of anti-CD20 antibodies onto the nanoparticle surface, EDC and NHS reagents were used. $\mathrm{EDC} \cdot \mathrm{HCl}(1 \mathrm{mg} / \mathrm{mL})$ was added to $5 \mathrm{~mL}$ of the prepared ACNP-DOX-DSPE-PEG2000-NH 2 or ACNPDSPE-PEG2000- $\mathrm{NH}_{2}$ and $200 \mu \mathrm{L}$ of anti-CD20 antibody $(10 \mathrm{mg} / \mathrm{mL})$. Following gentle mixing for 30 minutes at room temperature, the $\mathrm{pH}$ of the reaction solution was adjusted to 8.5 with $\mathrm{NaOH}$ solution. Next, $1.7 \mathrm{mg}$ of NHS was added to the reaction solution and the solution was stirred for 2 hours at room temperature. The solution was dialyzed for 12 hours in PBS (pH 7.4) using a $100 \mathrm{kDa}$ dialysis bag for 12 hours, to obtain the final product, which was the monoclonal antibody targeted NDDS, ACNP-DOX-DSPEPEG2000-anti-CD20.

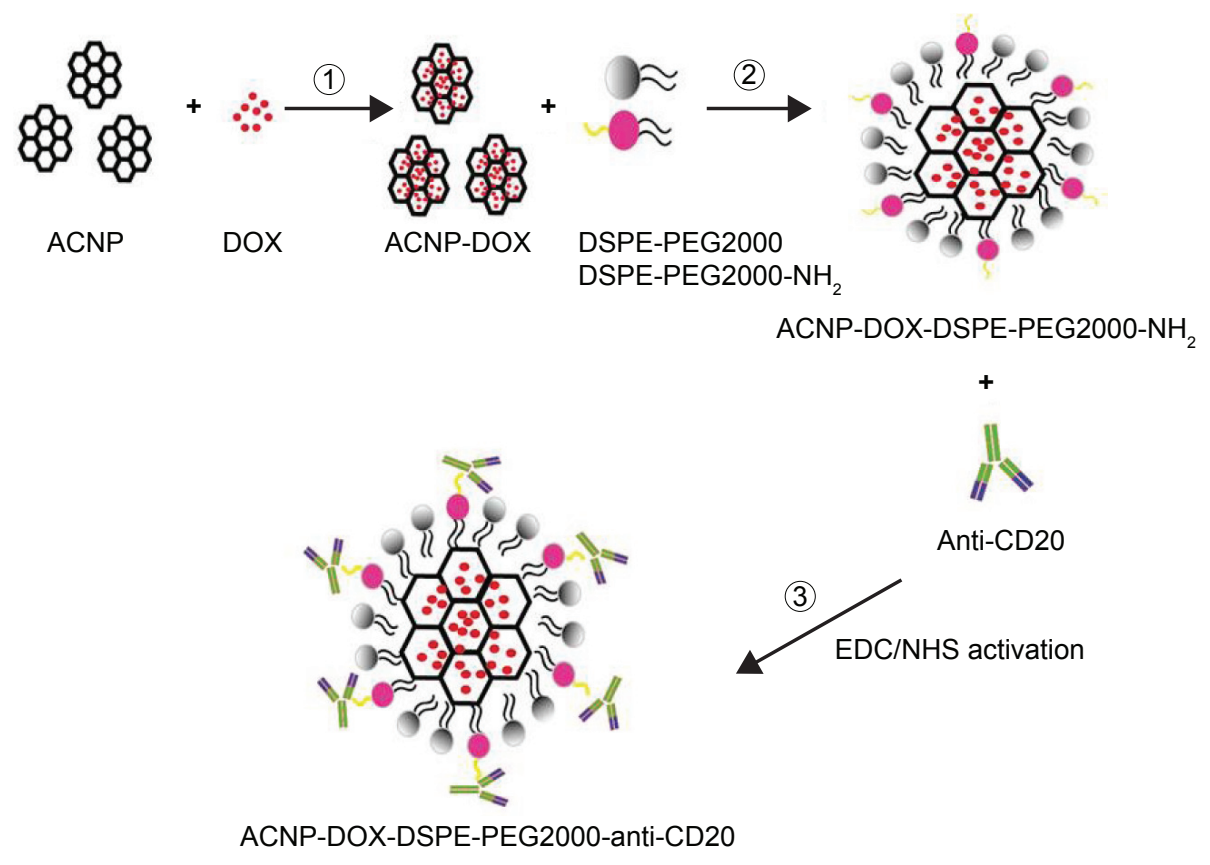

Figure I Preparation of ACNP-DOX-DSPE-PEG2000- $\mathrm{NH}_{2}$ conjugated anti-CD20.

Abbreviations: ACNP, active carbon nanoparticles; DOX, doxorubicin; DSPE, I,2-distearoyl-sn-glycero-3-phosphoethanolamine; EDC, I-ethyl-3-(3-dimethylaminopropyl) carbodiimide; NHS, N-hydroxysuccinimide; PEG, polyethylene glycol. 


\section{Determination of the DOX release rate from the DDS}

For each complex, $5 \mathrm{mg}$ of ACNP-DOX, ACNP-DOX-DSPE PEG2000 and ACNP-DOX-DSPE-PEG2000-anti-CD20 were each dispersed in $2 \mathrm{~mL}$ of $\mathrm{PBS}$ at $\mathrm{pH} 7.4$ and $\mathrm{pH} 5.5$ and transferred to disposable 3,500 $\mathrm{kDa}$ molecular weight cut-off dialysis bags, which were sealed and then immersed in $20 \mathrm{~mL}$ of release medium with vortex mixing at $100 \mathrm{rpm}$ at $37^{\circ} \mathrm{C}$. A $1 \mathrm{~mL}$ volume of release medium was taken at predetermined time intervals, followed by immediately supplementing an equal volume of fresh medium. The concentration of released DOX in the medium was determined by UV-visible spectroscopy, and the amount of released DOX (W) was calculated using the formula:

$$
\mathrm{W}=\mathrm{VC}
$$

where $\mathrm{V}$ was the volume of medium and $\mathrm{C}$ was the DOX concentration in the medium.

The cumulative release rate (RR, \%) was calculated using the formula:

$$
\mathrm{RR} \%=\frac{\mathrm{W}_{\mathrm{i}}}{\mathrm{W}_{\mathrm{t}}} \times 100
$$

where $\mathrm{W}_{\mathrm{i}}$ is the measured amount of DOX in the release medium at the given time point, and $\mathrm{W}_{\mathrm{t}}$ is the total DOX amount in the equal volume of ACNP suspensions before dialysis. Each experiment was repeated in triplicate. ${ }^{34}$

\section{Characterization of the NDDS, ACNP-DOX-DSPE- PEG2000-anti-CD20}

The particle size, polydispersity index, and zeta potential values were measured using Nano Series Zen 4003 Zetasizer (Malvern Instruments Ltd). ${ }^{33}$ The suspension stability of ACNP, ACNP-DOX, ACNP-DSPE-PEG2000, ACNPDOX-DSPE-PEG2000 and the NDDS, ACNP-DOXDSPE-PEG2000-anti-CD20 in PBS (10 mM, pH 7.4) were observed by mixing $1 \mathrm{mg}$ of corresponding preparation in $2 \mathrm{~mL}$ of PBS, followed by sonication for 30 minutes at room temperature.

The stability of the compound was evaluated after 1 month. The size and morphology of the ACNP-DOX, ACNP-DSPE-PEG2000, ACNP-DOX-DSPE-PEG2000 and the NDDS, ACNP-DOX-DSPE-PEG2000-anti-CD20 were evaluated using transmission electron microscopy (TEM) (Hitachi H7650, Hitachi Ltd., Tokyo, Japan). Each $0.1 \mathrm{mg} / \mathrm{mL}$ of sample was resuspended in water and mixed by sonication for 30 seconds. One drop of this suspension was placed on a carbon-coated copper TEM grid (200 mesh, Sangerbio, People's Republic of China) and allowed to dry at room temperature. The samples were imaged at $80 \mathrm{kV}$ with TEM. The absorption spectra were recorded in the range 200-900 nm using a UV-visible absorption spectrometer. Fluorescence spectra were recorded by a FluoroLog steadystate spectrofluorometer (excitation at $488 \mathrm{~nm}$ ) with the same DOX concentration. ${ }^{34}$

\section{Cell cultures}

Raji cells, derived from human Burkitt's lymphoma, were obtained from the Shanghai Institute of Cell Biology, Shanghai, People's Republic of China, and were cultured in Roswell Park Memorial Institute 1640 medium (Gibco, Billings, MT, USA) supplemented with $10 \%$ heat-inactivated fetal bovine serum (Gibco) and antibiotics (penicillin $100 \mathrm{U} / \mathrm{mL}$, and streptomycin $100 \mu \mathrm{g} / \mathrm{mL}) .{ }^{35}$ Cells were cultured in $5 \% \mathrm{CO}_{2}$ at $37^{\circ} \mathrm{C}$. Cells were passaged every 2 days, and cells in logarithmic growth phase were used for experiments. The YTS cell line, derived from human natural killer/T-cell lymphoma (kindly donated by Scott Kaufmann, Mayo Clinic, Rochester, MN, USA), was cultured in the same way as for the Raji cells.

\section{CD20-positive expression rate of Raji and YTS cells}

Following the addition of $50 \mu \mathrm{L}$ of $1.55 \mathrm{mg} / \mathrm{mL}$ FITC-anti$\mathrm{CD} 20$ to $100 \mu \mathrm{L}$ of Raji or YTS cell suspension, the unstained cell suspension and FITC-anti-CD20-labeled cell suspension were incubated simultaneously in the dark for 2 hours at $37^{\circ} \mathrm{C}$. The incubated cell suspensions were centrifuged at $900 \mathrm{rpm}$ for 3 minutes, the supernatant was removed, the cells were washed twice with PBS, and the number of CD20positive cells was measured using flow cytometry.

\section{Atomic force microscopy}

Preparation of the coverslips coated with L-poly-lysine

The coverslips were washed with $75 \%$ ethanol and soaked in $1 \mathrm{mg} / \mathrm{mL}$ L-poly-lysine PBS solution for 2 hours at room temperature. The coverslips were gently washed five times with triple-distilled water to remove excess L-poly-lysine and then dried. The $100 \mu \mathrm{L}$ of cell suspension was placed on prepared L-poly-lysine-coated coverslips for 2 minutes, followed by removal of the excess PBS, and the cells were fixed with $100 \mu \mathrm{L}$ of paraformaldehyde (4\%) for 15 minutes, washed five times with PBS, and three times with tripledistilled water, and air-dried.

\section{Observation of cells with atomic force microscopy}

The cells were observed using high-resolution, tapping mode NanoWizard atomic force microscopy (AFM) (JPK 
Instruments AG, Berlin, Germany). RTESP silicon AFM probes with spring constants of $40 \mathrm{~N} / \mathrm{m}$ (Veeco, Santa Barbara, CA, USA) were used for scanning in the air. The scan frequency was $1 \mathrm{~Hz}$. The ambient temperature was kept at $25^{\circ} \mathrm{C}$ with humidity $<30 \%$. Images were processed using AFM offline data processing software.

\section{Effects of the NDDS, ACNP-DOX-DSPE-PEG2000-} anti-CD20 on Raji cells and YTS cells in vitro

To observe the morphological cell changes brought about by the use of the NDDS, ACNP-DOX-DSPE-PEG2000-antiCD20, Raji and YTS cells were seeded into 6-well plates at a density of $2.5 \times 10^{5}$ cells/well. Cells were cultured in an incubator at $37^{\circ} \mathrm{C}$ in the presence of $5 \% \mathrm{CO}_{2}$. When the cells achieved exponential cell proliferation, formulations of the NDDS, ACNP-DOX-DSPE-PEG2000-anti-CD20 were added to the cell cultures with a final DOX concentration of $1-10 \mu \mathrm{g} / \mathrm{mL}$.

At 48 hours after dosing, the cultured cells were imaged and photographed using light microscopy. The survival rate of cells was assessed using the MTT assay and was calculated using the following formula:

$$
\text { Survival } \%=\frac{A_{570} n m \text { for the treated cells }}{A_{570} n m \text { for the control cells }} \times 100
$$

where $\mathrm{A}_{570} \mathrm{~nm}$ is the absorbance value. The dose-effect curves were plotted. All the experiments were performed in triplicate.

Drug targeting capability of the NDDS, ACNP-DOXDSPE-PEG2000-anti-CD20 on cultured Raji cells The intracellular targeting efficiency of the NDDS, ACNPDOX-DSPE-PEG2000-anti-CD20 complex was assessed by flow cytometry. Raji or YTS cells were seeded into 6-well culture plates with a density of $2.5 \times 10^{5}$ cells/well and cultured for 24 hours at $37^{\circ} \mathrm{C}$. The cells were treated with ACNP-DOX or the NDDS, ACNP-DOX-DSPE-PEG2000-anti-CD20 at a concentration of $10 \mathrm{mM}$ DOX. After incubation for 3 hours, the cells were resuspended in PBS.
The fluorescence intensities of DOX in cells were examined by FACScan (Becton Dickinson, San Jose, CA, USA) flow cytometry (excitation at $488 \mathrm{~nm}$; emission at 590 $\mathrm{nm})$. In a competition assay, the cells were preincubated with $5 \mathrm{mg} / \mathrm{mL}$ anti-CD20 antibodies for 30 minutes to saturate the cell surface CD20 antigens, before ACNP-DOX or the NDDS, ACNP-DOX-DSPE-PEG2000-anti-CD20 were added. For a qualitative analysis of the ability of the NDDS to target the B cells, CD20-positive Raji cells or CD20negative YTS cells were seeded into 6-well culture plates and treated with ACNP-DOX or the NDDS, ACNP-DOXDSPE-PEG2000-anti-CD20 as described earlier. Following 3 hours of incubation, the drug-treated cells were washed with PBS and fixed with 4\% (v/v) paraformaldehyde, followed by (blue fluorescence) cell nuclear staining with Hoechst 33258. The cells were examined by confocal laser scanning microscopy (Leica, Heidelberg, Germany). ${ }^{34}$

\section{Statistical analysis}

Data were presented as mean \pm standard deviation.

\section{Results and discussion}

Particle size of the NDDS, ACNP-DOX-DSPEPEG2000-anti-CD20

As shown in Table 1, the particle size of ACNP-DOX was $140.2 \pm 19.1 \mathrm{~nm}$, being almost the same as that of ACNP $(138.6 \pm 28.6 \mathrm{~nm})$, indicating that the loading of DOX had not changed the size of the particles significantly, because DOX was loaded into the micropores of the ACNP.

The particle size of ACNP-DOX conjugated to DSPEPEG2000 and the anti-CD20 antibody to form the NDDS, ACNP-DOX-DSPE-PEG2000-anti-CD20 was 290.2 $21.5 \mathrm{~nm}$, larger than that of ACNP-DOX-DSPE-PEG2000 $(202.9 \pm 17.3 \mathrm{~nm})$ and ACNP-DOX (140.2 $\pm 19.1 \mathrm{~nm})$.

\section{Morphology of the NDDS, ACNP-DOX-DSPE- PEG2000-anti-CD20}

TEM showed that modification of ACNP changed the morphology of the formulation (Figure 2A). ACNP and ACNPDOX particles were irregular in shape (Figure 2A1 and A2).

Table I Physicochemical characterization of different complexes (data represent mean $\pm S D, n=3$ )

\begin{tabular}{lllll}
\hline Formulation & Particle size $(\mathbf{n m})$ & Polydispersity index & Zeta potential $(\mathbf{m V})$ & DL\% \\
\hline ACNP & $138.6 \pm 28.6$ & $0.350 \pm 0.3$ & $-49.8 \pm 1.50$ & \\
ACNP-DOX & $140.2 \pm 19.1$ & $0.369 \pm 0.1$ & $-41.6 \pm 2.66$ & $31.2 \pm 2.64$ \\
ACNP-DOX-DSPE-PEG2000 & $202.9 \pm 17.3$ & $0.31 \pm 0.5$ & $-30.7 \pm 1.8$ & $29.8 \pm 2.56$ \\
ACNP-DOX-DSPE-PEG2000-anti-CD20 & $290.2 \pm 21.5$ & $0.413 \pm 0.4$ & $-6.72 \pm 1.1$ & $20.1 \pm 1.62$ \\
\hline
\end{tabular}

Abbreviations: ACNP, active carbon nanoparticles; DL, drug loading; DOX, doxorubicin; DSPE, I,2-distearoyl-sn-glycero-3-phosphoethanolamine; PEG, polyethylene glycol; SD, standard deviation. 
A
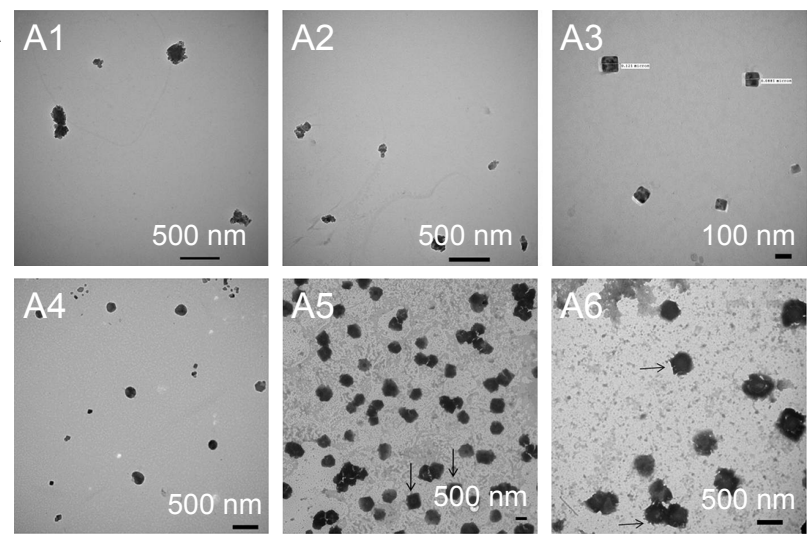

B

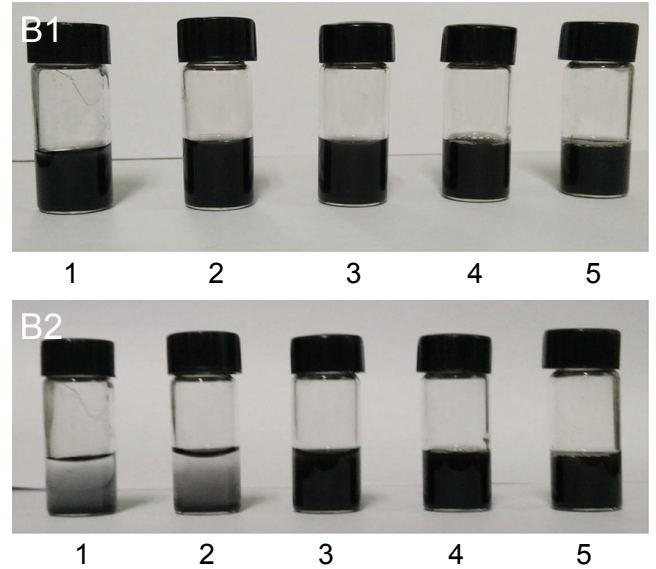

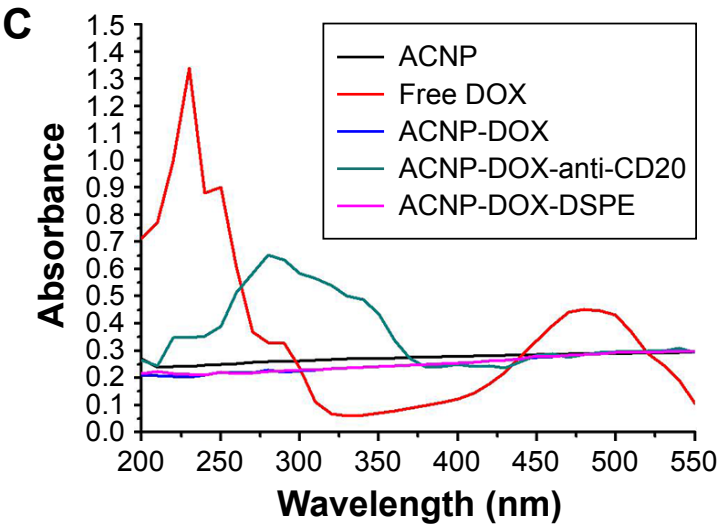

D kDa

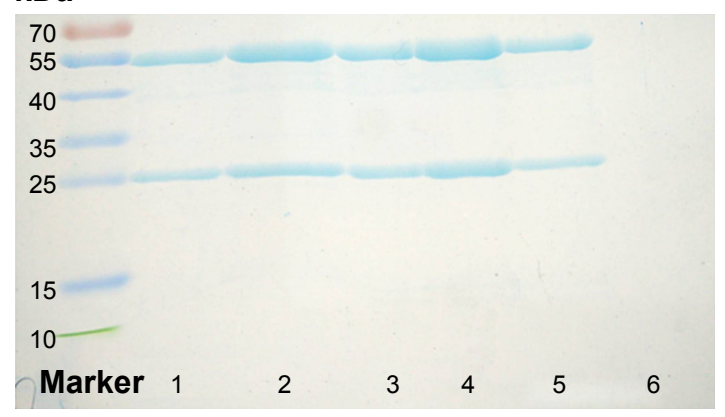

E
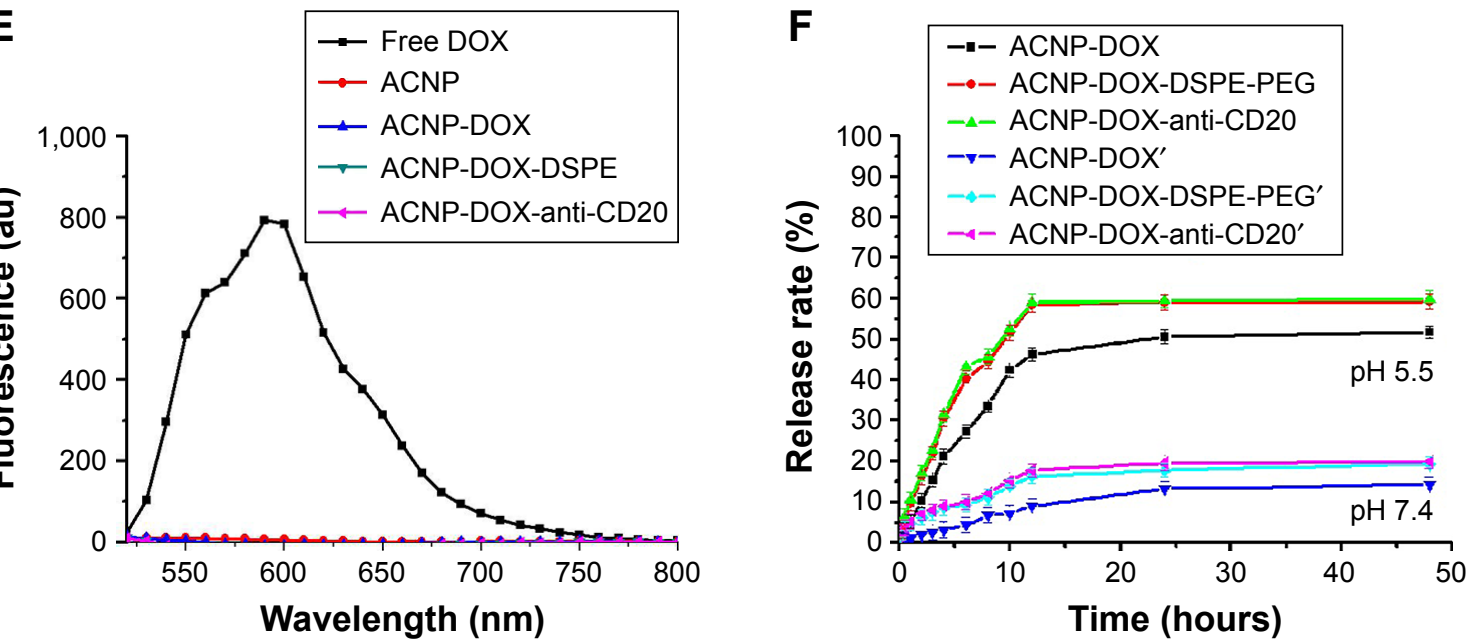

Figure 2 ACNP-DOX-DSPE-PEG2000-anti-CD20 NDDS characterization.

Notes: (A) The images of TEM show that modification of ACNP changed the morphology of the formulation. ACNP (AI) and ACNP-DOX (A2) particles were irregular in shape. ACNP-DOX-DSPE-PEG2000 (A3) particles had a cubic morphology with good dispersion stability. ACNP-DOX-DSPE-PEG2000-anti-CD20 (A4) particles were spherical in shape. There were no projections on the stained cubic particles of ACNP-DOX-DSPE-PEG2000, and they are indicated by black arrows (A5). However, cilialike projections could be seen on the surface of the stained spherical particles of ACNP-DOX-DSPE-PEG2000-anti-CD20, and they are indicated by black arrows (A6). The samples of AI, A2, A3, and A4 were not negative-stained during preparation process, and A5, A6 were stained with I\% uranyl acetate. (B) The dispersion and stability of blank ACNP (I), ACNP-DOX (2), ACNP-DOX-DSPE-PEG2000 (3), ACNP-DSPE-PEG2000 (4), and ACNP-DOX-DSPE-PEG2000-anti-CD20 (5) in pH 7.4 PBS. The solutions were put at $4{ }^{\circ} \mathrm{C}$ for over I month. ACNPs had aggregated and settled to the bottom of the ampule in the ACNP and ACNP-DOX groups, but no precipitates were seen at the bottom of containers in ACNP-DSPE-PEG2000, ACNP-DOX-DSPE-PEG2000 and ACNP-DOX-DSPE-PEG2000-anti-CD20 groups (B2).The original concentration of them was $0.5 \mathrm{mg} / \mathrm{mL}$. (C) UV-Vis absorption spectra of DOX, ACNP, ACNP-DOX and ACNP-DOX-DSPE-PEG2000-anti-CD20. The wavelength of maximum absorption peak was $480 \mathrm{~nm}$ for free DOX, and $254 \mathrm{~nm}$ for ACNP-DOX-DSPE-PEG2000-anti-CD20. There were no maximum absorption peaks for the other three samples. (D) SDS-PAGE analysis showed that the first, second, third, and fourth lanes included the big and small subunits of free anti-CD20 antibodies; the fifth lane included the subunits of anti-CD20 in ACNP-DOX- DSPE-PEG2000-anti-CD20; the sixth lane had no subunits of anti-CD20 in ACNP-DOX-DSPE-PEG2000 (ACNP unconjugated from anti-CD20). (E) Fluorescence spectra of DOX, ACNP, ACNP-DOX and ACNP-DOX-DSPE-PEG2000-anti-CD20. Only free DOX was found to have a strong fluorescence at 590 nm. (F) The in vitro release profile of DOX from ACNP-DOX, ACNP-DOX-DSPE, and ACNP-DOX-DSPE-antiCD20 with similar cumulative release behavior in pH 7.4 and 5.5 PBS. The release rates of DOX were no more than $20 \%$ in $\mathrm{pH} 7.4 \mathrm{PBS}$ at $37^{\circ} \mathrm{C}$ during 48 hours, but at $\mathrm{pH} 5.5$ they were $60 \%$ within 12 hours.

Abbreviations: au, astronomical unit; ACNP, active carbon nanoparticles; DOX, doxorubicin; DSPE, I,2-distearoyl-sn-glycero-3-phosphoethanolamine; PEG, polyethylene glycol; UV-Vis, ultraviolet-visible. 
Because carbon particles aggregate, they could only be seen at the edge of the copper mesh. ACNP-DOX, modified with DSPE-PEG2000 had a cubic morphology with good dispersion stability, as uniformly dispersed carbon particles could be seen under TEM (Figure 2A3). ACNP-DOX conjugated with the anti-CD20 antibody formed particles that were spherical in shape, as shown in Figure 2A4.

In order to demonstrate the morphology more clearly, the samples were negatively stained. There were no projections on the stained cubic particles of ACNP-DOX-DSPE-PEG2000 (Figure 2A5). However, cilia-like projections could be seen on the surface of the stained spherical particles of the NDDS, ACNP-DOX-DSPE-PEG2000-anti-CD20 (Figure 2A6). Although it was not possible to determine what these cilialike projections were, it is possible that they may represent the available anti-CD20 antibodies on the surface of the ACNP-DOX-DSPE-PEG2000 complex.

\section{Stability of the NDDS,ACNP-DOX-DSPE-PEG2000- anti-CD20}

After the prepared formulations (Figure 2B1) had been placed in an ampoule at room temperature for 1 month, it was observed that the ACNPs had aggregated and settled to the bottom of the ampoule in the ACNP and ACNP-DOX groups, but no precipitates were seen at the bottom of containers in ACNPDSPE-PEG2000, ACNP-DOX-DSPE-PEG2000, and ACNPDOX-DSPE-PEG2000-anti-CD20 groups (Figure 2B2).

In the early preliminary experiments, it was found that the unmodified ACNP in the suspension would settle to the bottom of the ampoule in less than half an hour, whether in water or salt solution. These results demonstrated that the unmodified ACNP suspension had poor stability, and the loading of DOX did not improve the dispersion of ACNP. The structures of the DSPE-PEG2000 and DSPE-PEG2000-anti-CD20 satisfactorily improved the stability of the ACNP suspension.

\section{Confirmation of the conjugation of the components the NDDS, ACNP-DOX-DSPE- PEG2000-anti-CD20}

DOX showed a characteristic UV absorbance peak at $480 \mathrm{~nm}$ (Figure 2C), which disappeared when DOX was adsorbed in the pores of the ACNP. The ACNP, ACNP-DOX, and ACNPDOX-DSPE complexes had no absorbance at 200-500 nm and only ACNP-DOX-DSPE-anti-CD20 had a significant absorption peak at $254 \mathrm{~nm}$.

Sodium dodecylsulfate polyacrylamide gel electrophoresis was used to determine whether antibodies were conjugated with the nanoparticles. Figure 2D shows that the first, second, third, and fourth lanes of the gel include concentrations of 2, 4,
3, and $6 \mu \mathrm{g} / \mathrm{mL}$ of anti-CD20 antibodies; the fifth lane includes the NDDS, ACNP-DOX-DSPE-PEG2000-anti-CD20; the sixth lane shows ACNP-DOX-DSPE-PEG2000 (ACNP unconjugated from anti-CD20). The coupling efficiency of anti-CD20 antibody was found to be $20.23 \% \pm 2.5 \%$.

\section{DL of the NDDS, ACNP-DOX-DSPE-PEG2000- anti-CD20}

Figure 2E shows that free DOX was found to have a strong fluorescence at $590 \mathrm{~nm}$, which was not seen with other ACNP preparations using fluorescence spectrophotometry. Figure $2 \mathrm{~F}$ shows the in vitro release profiles of DOX from ACNP-DOX, ACNP-DOX-DSPE-PEG2000 and the NDDS, ACNP-DOX-DSPE-PEG2000-anti-CD20, which were investigated in $\mathrm{pH} 7.4$ and $5.5 \mathrm{PBS}$ at $37^{\circ} \mathrm{C}$, with similar cumulative release behavior (Figure $2 \mathrm{~F}$ ). The release rates were no more than $20 \%$ in $\mathrm{pH} 7.4 \mathrm{PBS}$ at $37^{\circ} \mathrm{C}$ during 48 hours, but at pH 5.5 they were $60 \%$ within 12 hours.

This $\mathrm{pH}$ triggering effect could be because, in acidic $\mathrm{pH}$ conditions, DOX is positively charged and water soluble, and the $-\mathrm{COOH}$ on the surface of ACNP could be acidified, thereby reducing the drug-ACNP interactions to allow DOX to be released from the ACNP. The ACNP modified with DSPE-PEG2000 reduced the aggregation in aqueous solution to increase the release of DOX. This $\mathrm{pH}$-sensitive release of DOX may be significant because of the acidic microenvironments found in tumor tissues and cell lysosomes. ${ }^{36}$

The DL content of DOX in the NDDS, ACNP-DOXDSPE-PEG2000-anti-CD20 was $20.1 \% \pm 1.6 \%$, which was less than that for the ACNP-DOX-DSPE-PEG2000 complex $(29.8 \% \pm 2.56 \%)$ and the ACNP-DOX complex $(31.2 \% \pm 2.64 \%)$, as shown in Table 1 , which may be attributed to the increasing size of the complex, including the additional conjugated antibody.

The zeta potential measurements $(-6.72 \pm 1.1 \mathrm{mV})$ also supported the integrity of the preparation process of the NDDS, ACNP-DOX-DSPE-PEG2000-anti-CD20, as shown in Table 1 .

\section{Effects of the NDDS,ACNP-DOX-DSPE-PEG2000-} anti-CD20 on Raji cells in vitro

The Raji cells, which are positive for cell membrane expression of CD20, grew in vitro in cohesive clusters (Figure 3A1). The YTS cells were larger than the Raji cells and were less cohesive when grown in vitro (Figure 3A2).

AFM showed the surface characteristics of both the Raji and YTS cells, and showed that the Raji cell membrane appeared to be pitted (Figure 3A3 and A4). The YTS cells were larger than the Raji cells and had a smooth surface 

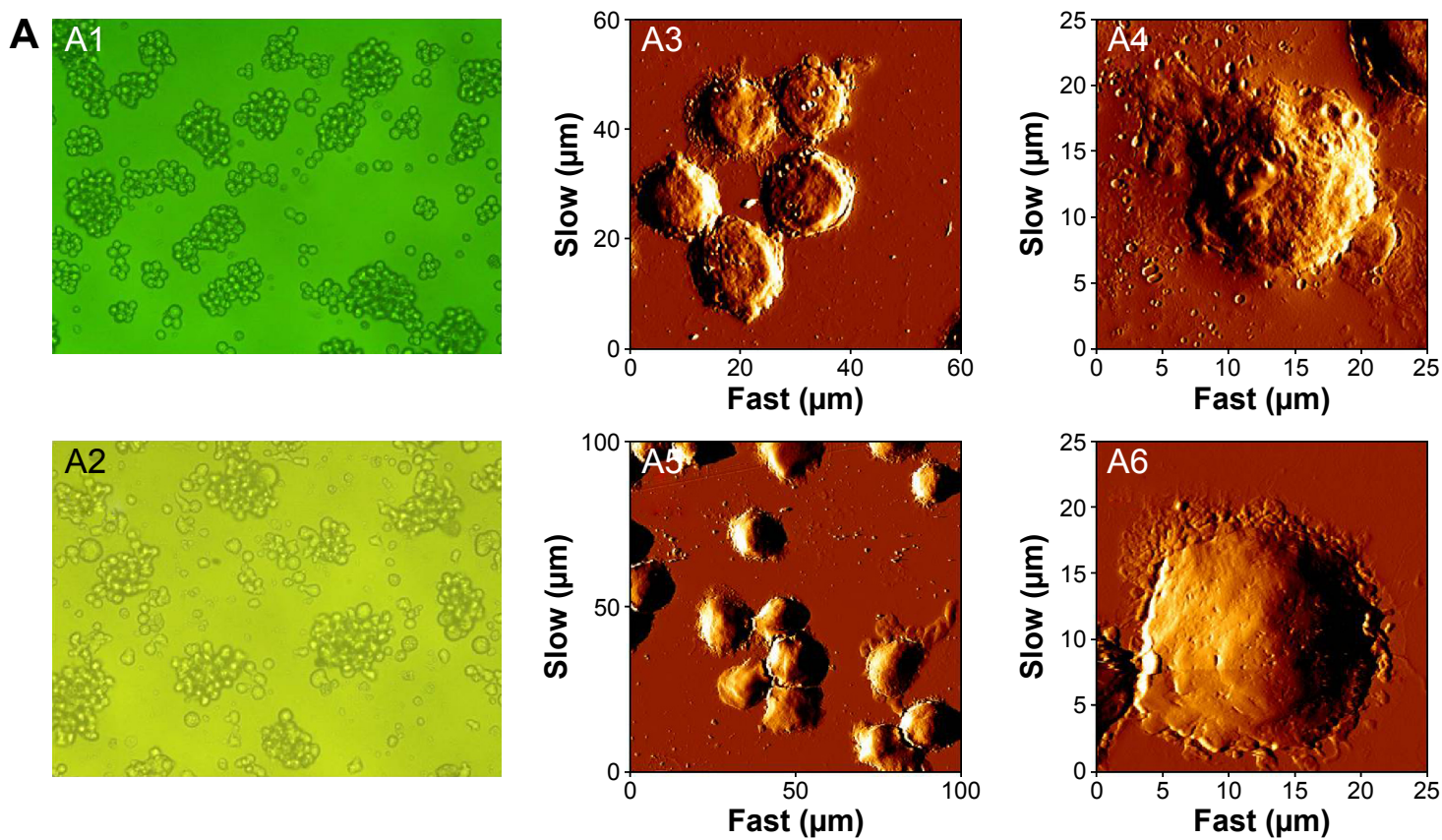

B
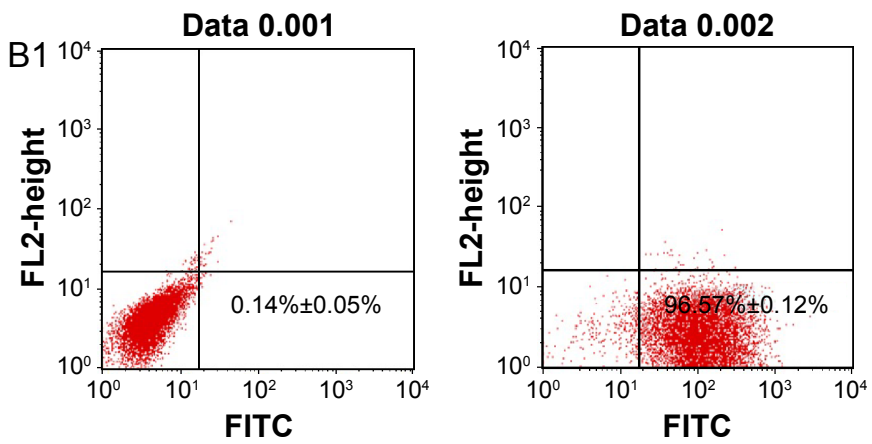

Raji

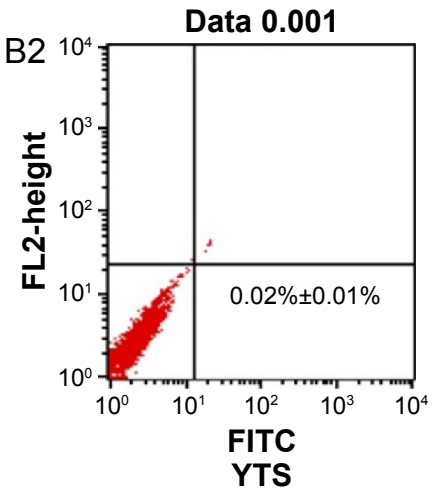

Raji + FITC-anti-CD20

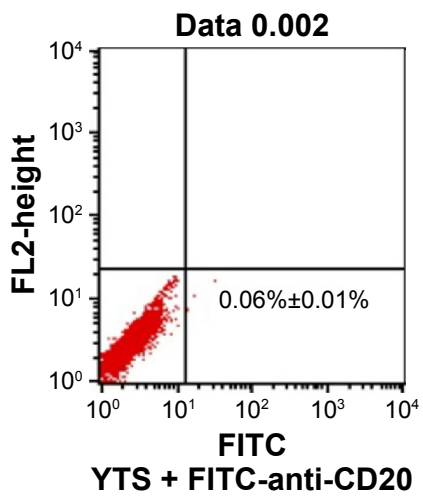

Figure 3 Morphology and characteristic marker identification of normal Raji (CD20+) cells and YTS (CD20-) cells.

Notes: (A) The images of light microscopy showed normal Raji grew in cohesive clusters (AI, $\times 200)$, and normal YTS cells were larger than Raji cells and were less cohesive when grown (A2, $\times 200)$. The images of AFM showed that the surface characteristics of Raji cells membrane appeared to be pitted (A3 and A4) and YTS cells were larger than Raji cells and had a smooth surface (A5 and A6). A4 and A6 are high-resolution single cell images of Raji and YTS cells, respectively. The image size of A3 is $60 \mu \mathrm{m} \times 60 \mu \mathrm{m}$, and the image size of A4 is $25 \mu \mathrm{m} \times 25 \mu \mathrm{m}$; the image size of A5 is $100 \mu \mathrm{m} \times 100 \mu \mathrm{m}$, and the image size of A6 is $25 \mu \mathrm{m} \times 25 \mu \mathrm{m}$. (B) Flow cytometry analysis of the positive rates of CD20 antigen of Raji (BI) was $96.71 \%$ and that of $Y$ TS (B2) was $0.06 \%$, and data represent mean \pm SD, $n=3$.

Abbreviations: AFM, atomic force microscopy; FL2, fluorescence channel 2; FITC, fluorescein isothiocyanate; $\mu$ m, micrometer; SD, standard deviation.

(Figure 3A5 and A6). Figure 3A4 and A6 is a high-resolution single cell image of Raji and YTS cells, respectively.

Flow cytometry with FITC-labeling of the cells with anti-CD20 antibody showed that $96.71 \%$ of Raji cells were
CD20-positive (Figure 3B1) and that $0.06 \%$ of YTS cells were CD20-positive (Figure 3B2).

The possible cytotoxicity of the ACNPs was studied by toxicity testing of their in vitro effects. Figure 4A shows 
A

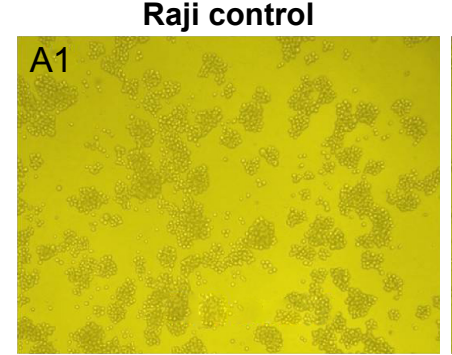

B
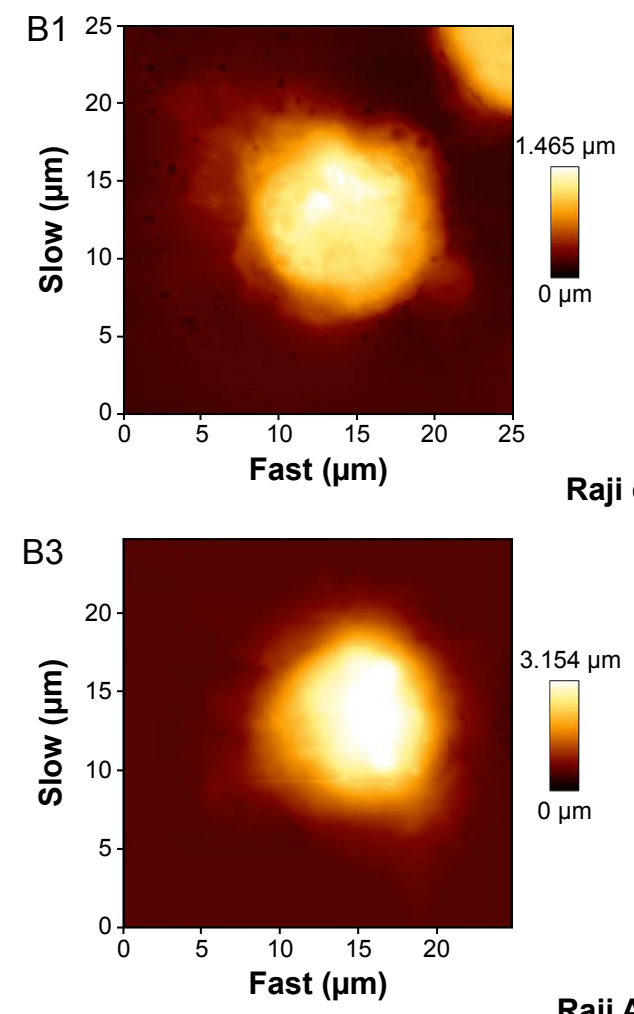

Raji ACNP

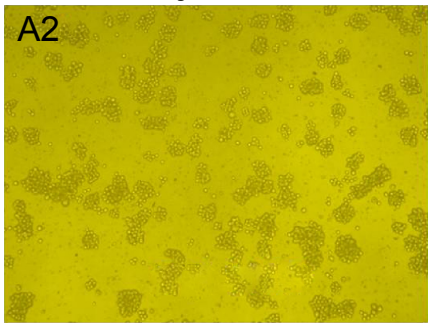

B2

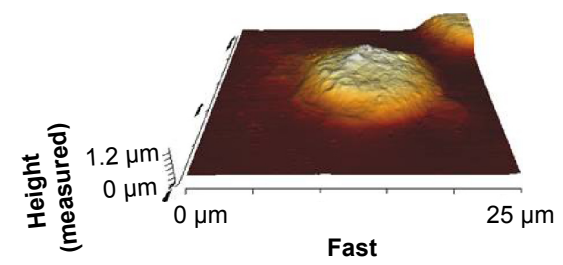

Raji control

B4

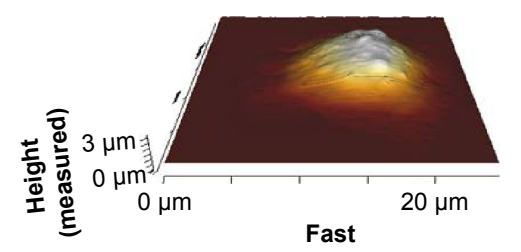

Raji ACNP

C

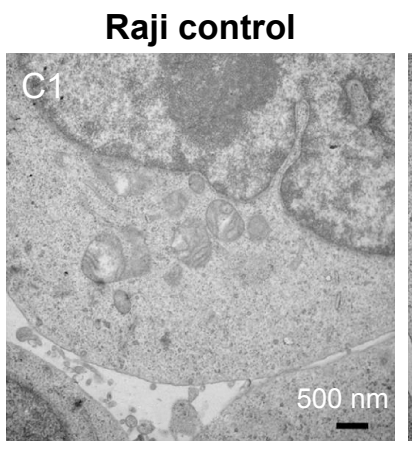

Raji ACNP

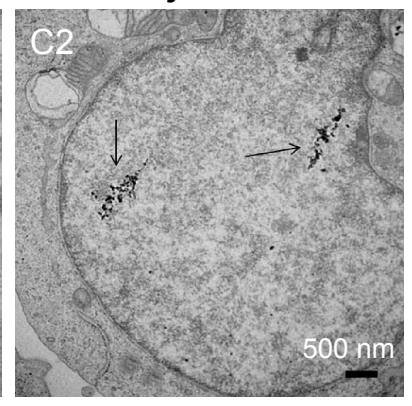

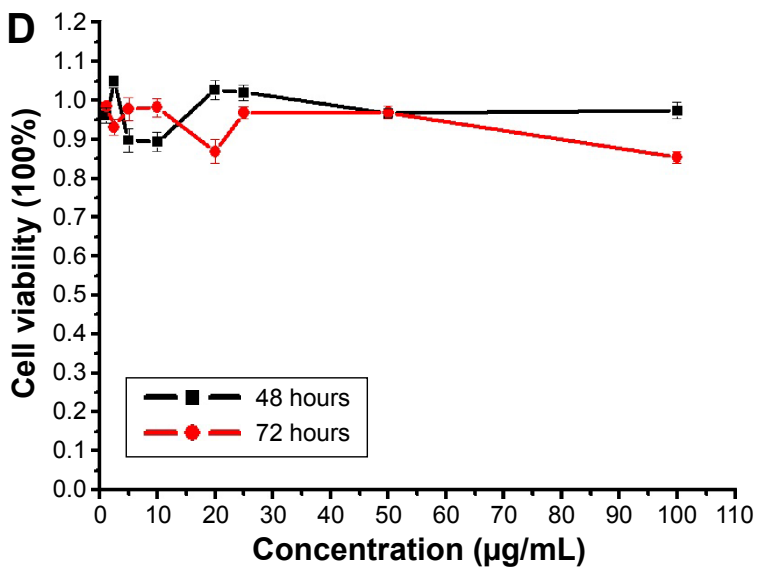

Figure 4 The cytotoxicity of ACNP on Raji cells (A) light microscopy (AI and A2, $\times 100$ ) (B) AFM (the image sizes of BI and B3 are $25 \times 25 \mu \mathrm{m}, \mathrm{B} 2$ and $B 4$ are their corresponding three-dimensional structures) (C) TEM (D) MTT.

Notes: (A) The light microscopic morphology of Raji cells cultured in $20 \mu \mathrm{g} / \mathrm{mL}$ ACNP for 72 hours, with comparison of the untreated Raji cells (AI) and the treated Raji cells (A2) (AI and A2, $\times I 00)$. (B) AFM showed that the surface of the Raji cells in the control group (BI and B2) showed no abnormalities when compared with the ACNPtreated group (B3 and B4) (the image sizes of BI and B3 are $25 \mu \mathrm{m} \times 25 \mu \mathrm{m}, \mathrm{B} 2$ and B4 are their corresponding 3D structures). (C) TEM demonstrated no differences in the ultrastructure of the nucleus and organelles between the untreated $(\mathrm{CI})$ and $\mathrm{ACNP}$-treated cells $(\mathrm{C} 2)$, although ACNPs were demonstrated to enter the cell (black arrows in C2). (D) The MTT assays showed that treatment with ACNP did not inhibit the growth of Raji cells even at the highest concentration (I00 $\mu g / m L)$, indicating that ACNP may be a potential drug delivery carrier that is without immediate cytotoxicity.

Abbreviations: AFM, atomic force microscopy; ACNP, active carbon nanoparticles; $\mu$ m, micrometer; MTT, 3-(4,5-Dimethylthiazol-2-yl)-2,5-diphenyltetrazolium bromide; TEM, transmission electron microscope. 
the light microscopic morphology of Raji cells cultured in $20 \mu \mathrm{g} / \mathrm{mL}$ ACNP for 72 hours, with comparison of the untreated Raji cells (Figure 4A1) and the treated Raji cells (Figure 4A2). AFM showed that the surface of the Raji cells in the control group (Figure 4B1 and B2) showed no abnormalities when compared with the ACNP-treated group (Figure 4B3 and B4). Figure 4C1 shows that TEM demonstrated no differences in the ultrastructure of the nucleus and organelles between ACNP-treated and untreated cells, although ACNPs were demonstrated to enter the cell (black arrows in Figure 4C2).

The MTT assays showed that treatment with ACNP did not inhibit the growth of Raji cells even at the highest concentration $(100 \mu \mathrm{g} / \mathrm{mL})$ (Figure 4D), indicating that ACNP may be a potential drug delivery carrier that is without immediate cytotoxicity.

Figure 5A shows the Raji and YTS cells morphological changes resulting from the inhibitory effects of the NDDS, ACNP-DOX-DSPE-PEG2000-anti-CD20, and the other formulations. Under light microscopy, control Raji (A1a) and YTS (A2a) cells grew in cohesive clusters, showing a strong proliferation activity. Compared with ACNP-DOX (Figure 5A1b and Figure 5A2b), ACNP-DOX-DSPEPEG2000 (Figure 5A1c and Figure 5A2c) showed stronger cell inhibitory effects on CD20-positive cells (Figure 5A1) and CD20-negative cells (Figure 5A2). However, the NDDS, ACNP-DOX-DSPE-PEG2000-anti-CD20 treated CD20positive cells grew in noncohesive groups and showed early cell lysis (Figure 5A1d), while the CD20-negative YTS cells continued to grow in cohesive groups (Figure 5A2d). Free DOX (Figure 5A1e and Figure 5A2e) showed the strongest cell inhibitory effects on Raji and YTS cells. Treatment with CD20 antibodies alone resulted in weak inhibitory effects on Raji and YTS cells (Figure 5A1f and Figure 5A2f).

Figure 5B shows the inhibitory effects of various formulations on CD20-positive Raji cells and CD20-negative YTS cells measured with the MTT assay. Figure 5B1 and B2 show that, among all the formulations used, free DOX had the strongest cytolytic effect on both Raji and YTS cells, indicating that DOX alone had no cell selectivity. This finding supports the nonselective chemotherapeutic toxicity of DOX seen clinically.

The inhibitory effect of the NDDS, ACNP-DOX-DSPEPEG2000-anti-CD20 on Raji cells was almost the same as that of free DOX (Figure 5B1), but had a milder effect on YTS cells than that of DOX alone (Figure 5B2), indicating that anti-CD20 conjugated NDDS had a targeted cytolytic effect on CD20-positive Raji cells.
The nonantibody conjugated complexes, ACNP-DOX and ACNP-DOX-DSPE-PEG2000, had mild inhibitory effects on both Raji cells and YTS cells, which was consistent with the characteristic of ACNP as a sustained-release drug carrier. In the MTT assays, the optical absorbance was the parameter that indicated cell viability. However, because the color of ACNPs is black, the measured optical absorbance values in high doses were greater than in low doses. These findings have demonstrated that the MTT assay using optical absorbance was of less value than light microscopic imaging for assessment of cell viability resulting from treatment with these ACNPs.

Figure 6A shows the uptake of DOX, which has mild autofluorescent properties, imaged using confocal laser microscopy to evaluate cells treated with various formulations. The control Raji cells (Figure 6Aa) had no red fluorescence of DOX found in their nuclei. The Raji cells treated with ACNPDOX (Figure 6Ab) had the weakest of red fluorescence in all the prepared complexes. The free DOX (Figure 6Ac) treated Raji cells had the strongest red fluorescence of DOX. The fluorescence concentration of DOX in the nuclei of Raji cells treated with the ACNP-DOX-DSPE (Figure 6Ad) was slightly stronger than the ACNP-DOX (Figure 6Ab), meaning that ACNP is a sustained-release drug carrier. The concentration of DOX in the nuclei of Raji cells treated with the NDDS, ACNP-DOX-DSPE-PEG2000-anti-CD20 (Figure 6Ae) was the greatest of all the prepared complexes and was equivalent to that of DOX treatment alone (Figure 6Ac). Pretreatment with the monoclonal anti-CD20 antibody(Figure 6Af), which blocked cell surface CD20, reduced the fluorescence of intracellular DOX. These results indicated that the targeting effect of the NDDS, ACNP-DOX-DSPE-PEG2000-anti-CD20 resulted from the selective improvement of intracellular DOX concentration in CD20-positive Raji cells.

In Raji cells, treatment with the NDDS, ACNP-DOXDSPE-PEG2000-anti-CD20 resulted in the second highest uptake of DOX (Figure 6B1), but in YTS cells, treatment resulted in the lowest amount of DOX uptake (Figure 6B2). These results indicated that the NDDS, ACNP-DOX-DSPEPEG2000-anti-CD20 had the most significant targeting effects on CD20-positive Raji cells.

Figure 6C shows the fluorescence microscopy observation of the morphology of cell apoptosis in Raji cells (Figure 6C1) and YTS cells (Figure 6C2) following treatment with various formulations of DOX (1 $\mu \mathrm{g} / \mathrm{mL})$ for 24 hours at $37^{\circ} \mathrm{C}$. The untreated cells (Figure 6C1a and C2a) showed no observable apoptosis, displaying normal nuclear morphology. Apoptotic cell morphology, appeared in the 
A

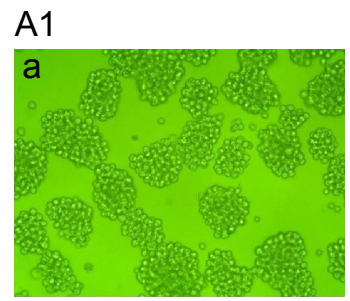

Control

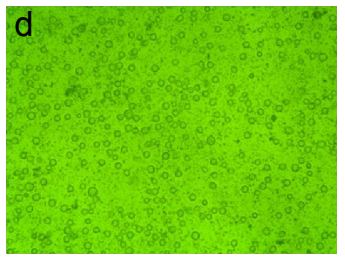

ACNP-DOX-DSPEPEG2000-anti-CD20

A2

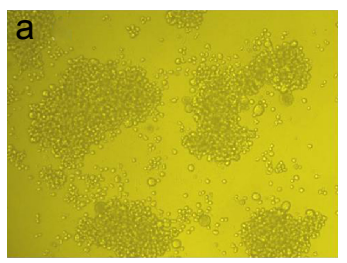

Control

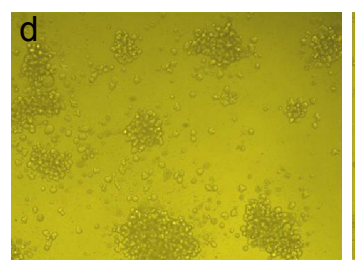

ACNP-DOX-DSPE-

PEG2000-anti-CD20

B

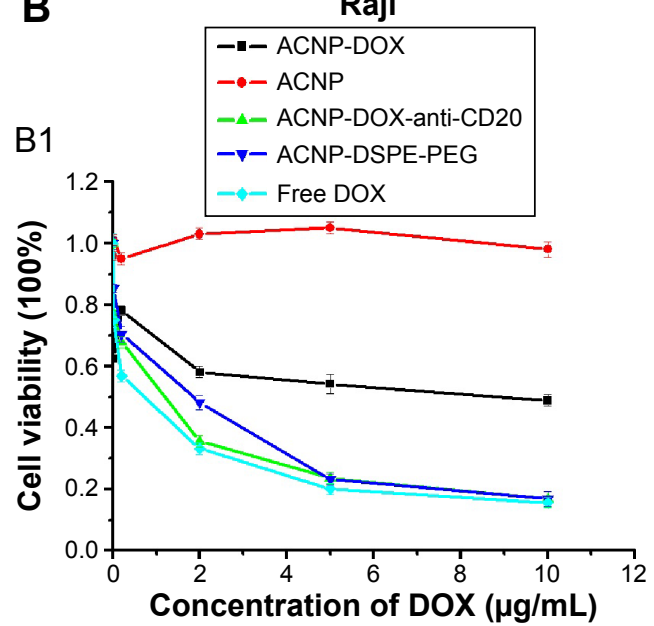

Raji

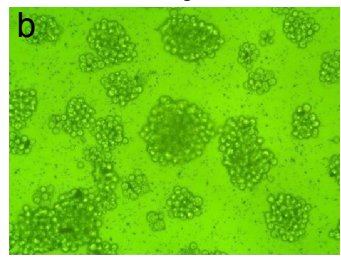

ACNP-DOX

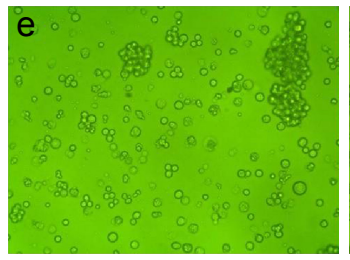

Free DOX

YTS

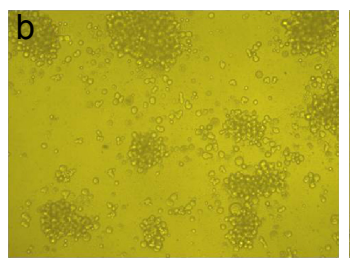

ACNP-DOX

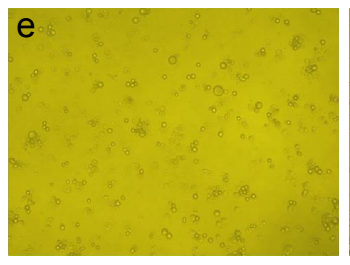

Free DOX

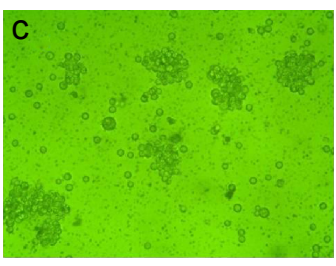

ACNP-DOX-DSPE-PEG2000

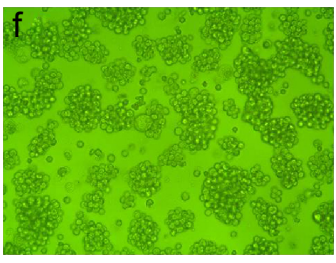

Free anti-CD20

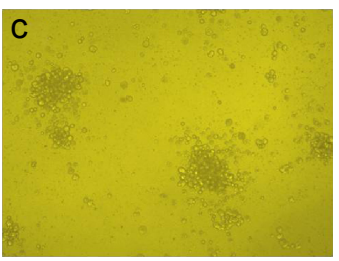

ACNP-DOX-DSPE-PEG2000

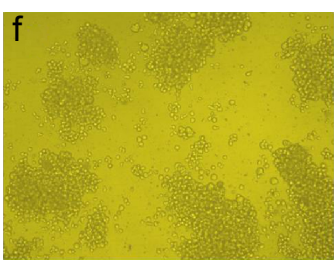

Free anti-CD20

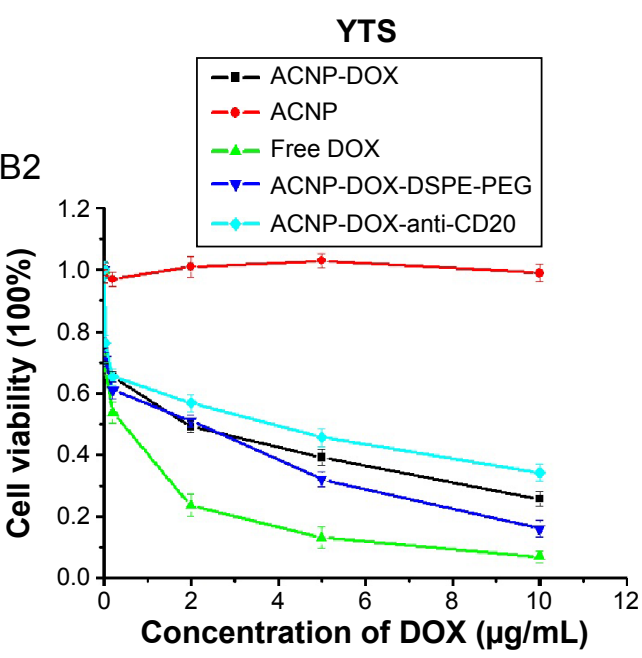

Figure 5 In vitro inhibitory effects of ACNP-DOX-DSPE-PEG2000-anti-CD20 on Rajis (AI, $\times 200)$ and YTS (A2, $\times 100)$ with light microscopy, Rajis (BI) and YTS $(B 2)$ with MTT. Notes: (A) Control Raji (Ala) and YTS (A2a) cells grew in cohesive clusters. Compared with ACNP-DOX (Alb, A2b), ACNP-DOX-DSPE-PEG2000 (Alc, A2c) showed strong cell inhibitory effects on Raji and YTS cells. ACNP-DOX-DSPE-PEG2000-anti-CD20 treated Raji (CD20-positive cells) grew in non-cohesive groups and showed early cell lysis (AId), while YTS cells (CD20-negative) continued to grow in cohesive groups (A2d). Free DOX (Ale, A2e) showed the strongest cell inhibitory effects on Raji and YTS. Treatment with CD20 antibodies alone resulted in weak inhibitory effects on Raji cells (Alf) and YTS cells (A2f). (B) Free DOX had the strongest cytolytic effect on both Raji (BI) and YTS (B2) cells, indicating that DOX alone had no cell selectivity. The inhibitory effect of the ACNP-DOX-DSPE-PEG2000-anti-CD20 on Raji cells was almost the same as that of free DOX (BI), but had a milder effect on YTS cells than that of DOX alone (B2), indicating that anti-CD20 conjugated NDDS had a targeted cytolytic effect on CD20-positive Raji cells. ACNP-DOX and ACNP-DOX-DSPE-PEG2000, had mild inhibitory effects on both Raji cells and YTS cells.

Abbreviations: ACNP, active carbon nanoparticles; DOX, doxorubicin; DSPE, I,2-distearoyl-sn-glycero-3-phosphoethanolamine; NDDS, nanoscale drug delivery system; PEG, polyethylene glycol. 
A

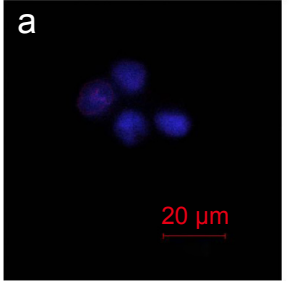

Control

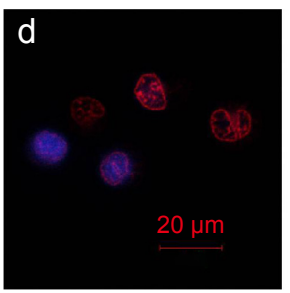

ACNP-DOX-DSPE

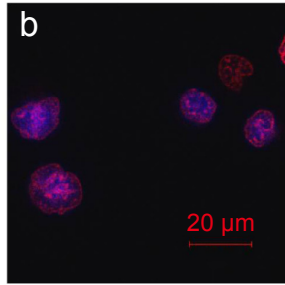

ACNP-DOX

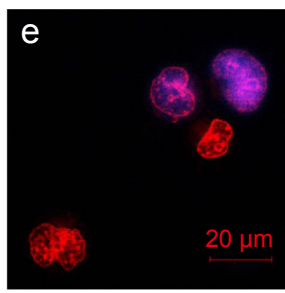

ACNP-DOX-DSPEanti-CD20

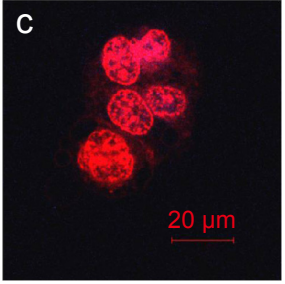

Free DOX

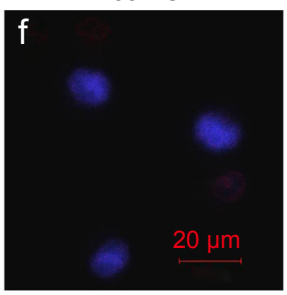

ACNP-DOX-DSPEanti-CD20 ${ }^{+}$anti-CD20
B

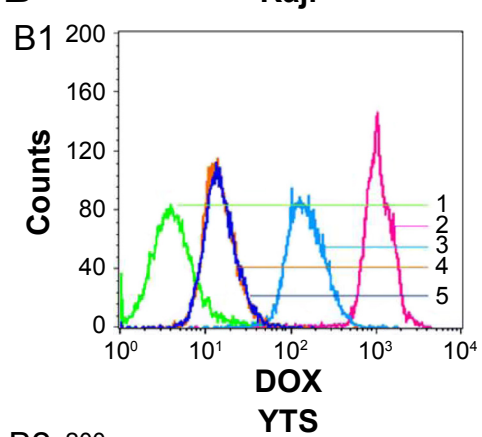

C C1

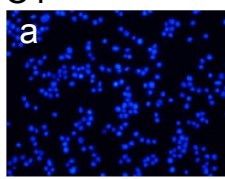

Control

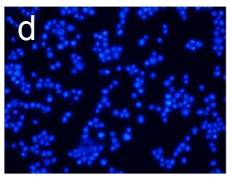

ACNP-DOX

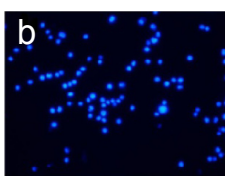

ACNP-DOXDSPE-PEG2000

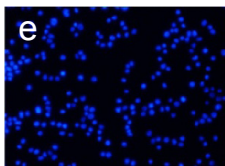

ACNP-DSPEPEG2000

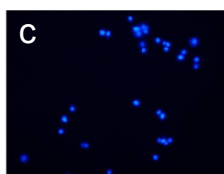

ACNP-DOX-DSPE PEG2000-anti-CD20

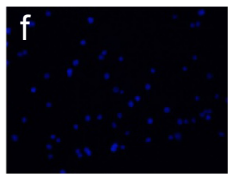

Free DOX

$\mathrm{C} 2$

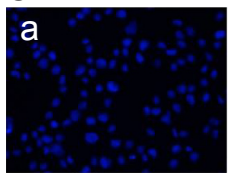

Control

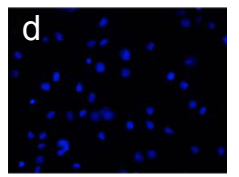

ACNP-DOX

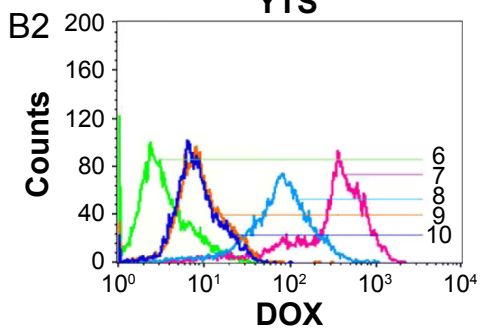

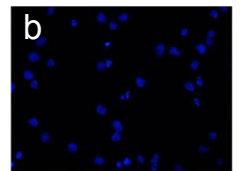

ACNP-DOX-

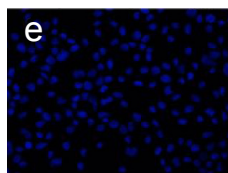

ACNP-DSPEPEG2000

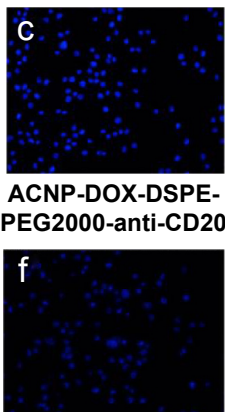

Free DOX

Figure 6 The targeting effect of ACNP-DOX-DSPE-PEG2000-anti-CD20.

Notes: (A) The control Raji cells (a) had no red fluorescence of DOX found in their nucleus. The Raji cells treated with ACNP-DOX (b) had the weakest of red fluorescence in all the prepared complexes. The Raji cells treated with free DOX (c) had the strongest red fluorescence found in their nucleus. The fluorescence concentration of DOX in the nuclei of Raji cells treated with ACNP-DOX-DSPE (d) was slightly stronger than ACNP-DOX (b), meaning that ACNP is a sustained-release drug carrier. Raji cells treated with ACNP-DOX-DSPE-PEG2000-anti-CD20 (e) had the greatest of all the prepared complexes and was nearly equivalent to that of DOX (c) treatment alone; pretreatment with the monoclonal anti-CD20 antibody $(\mathrm{f})$, which blocked cell surface CD20, reduced the fluorescence of intracellular DOX (Red represents fluorescence of DOX and blue is fluorescence of Hoechst 33258. (B) ACNP-DOX-DSPE-PEG2000-anti-CD20 resulted in the second highest uptake of DOX (BI), but in YTS cells, treatment resulted in the lowest amount of DOX uptake (B2) (I, control; 2, free DOX; 3, ACNP-DOX-DSPE-PEG2000-anti-CD20; 4, ACNP-DOX; 5, ACNP-DOX-DSPE-PEG2000; 6, control; 7, free DOX; 8, ACNP-DOX-DSPE-PEG2000; 9, ACNP-DOX; 10, ACNP-DOX-DSPE-PEG2000-anti-CD20). (C) Fluorescence microscopy observation of the morphology of cell apoptosis in Raji cells $(\mathrm{Cl})$ and YTS cells $(\mathrm{C} 2)$ following treatment with various formulations of DOX (I $\mu \mathrm{g} / \mathrm{mL})$. The untreated control cells $(\mathrm{Cla}$ and $\mathrm{C} 2 \mathrm{a})$ showed no observable apoptosis. Apoptotic cell morphology appeared in both Raji and YTS cells treated with ACNP-DOX-DSPE-PEG2000 complex (CIb and C2b). Only Raji cells (CIc) showed observable apoptosis when treated with ACNP-DOX-DSPE-PEG2000-anti-CD20, and apoptosis was not present in the YTS cells treated with ACNP-DOXDSPE-PEG2000-anti-CD20 (C2c), indicating that the antibody-conjugated nanoparticles have a selectivity for CD20-positive Raji cells. Apoptotic cell morphology appeared in ACNP-DOX(Cld and C2d). The ACNP-DSPE-PEG2000 treated cells (Cle and C2e) showed no observable apoptosis as the control cells. The Raji and YTS cells treated with noncomplexed free DOX alone (CIf and C2f) had the obvious apoptosis. ACNP-DOX and ACNP-DOX modified with DSPE-PEG2000 showed no selectivity for CD20-positive or CD20-negative cells.

Abbreviations: ACNP, active carbon nanoparticles; DOX, doxorubicin; DSPE, I,2-distearoyl-sn-glycero-3-phosphoethanolamine; PEG, polyethylene glycol.

ACNP-DOX-DSPE-PEG2000 complex (Figure 6C1b and $\mathrm{C} 2 \mathrm{~b}$ ) and the Raji cells treated with the NDDS, ACNP-DOXDSPE-PEG2000-anti-CD20 (Figure 6C1c). Apoptosis was not present in the YTS cells treated with the NDDS, ACNPDOX-DSPE-PEG2000-anti-CD20 (Figure 6C2c), indicating that the antibody-conjugated nanoparticles have a selectivity for CD20-positive Raji cells. The complexes, ACNP-DOX modified with DSPE-PEG2000 showed no selectivity for CD20-positive or CD20-negative cells. Also, the complex, ACNP-DOX (Figure 6C1d and $\mathrm{C} 2 \mathrm{~d}$ ) induced less early apoptosis than free DOX, indicating that ACNP is a sustainedrelease drug carrier. The ACNP-DSPE-PEG2000 treated cells (Figure 6C1e and $\mathrm{C} 2 \mathrm{e}$ ) showed no observable apoptosis as the control cells. These findings indicate that ACNP has low cytotoxicity, which supports the results described earlier from the MTT, AFM and microscopy studies. Apoptotic cell morphology, including nuclear chromatin condensation, nuclear condensation, the breakdown of nuclear membrane and formation of apoptotic bodies, appeared in both Raji and YTS treated with free DOX (Figure 6C1f and C2f). 
In clinical practice, B-cell lymphomas may become resistant to chemotherapy agents, even with increasing doses of treatment, and chemotherapy toxicity is common and may have serious consequences. Improved drug delivery systems with reduced toxicity and targeted specifically to B cells would be important clinically. This study shows that it is possible to develop an anti-CD20 antibody-conjugated ACNP-DOX, which results in a slower intracellular DOX concentration in ACNP-DOX treated B cells than in cells treated with DOX alone. Also, when this drug delivery complex is conjugated with a monoclonal antibody to CD20, the intracellular DOX concentration in treated CD20-positive B cells is almost the same as that in the cells treated with free DOX.

Although this is a small, preliminary in vitro study, it has shown the possibility of targeting the effects of an antibody-conjugated NDDS and the benefits of using the specific antigen-antibody interaction in drug delivery. The cell targeting of the antibody-conjugated NDDS ensures that the drug concentration around the target cells is greater than that around the nontarget cells. The increased drug concentration allows more cytotoxic drug delivery to the target cells, which offsets the influences of slower drug release by the NDDS. Although these findings have been demonstrated in a controlled and preliminary in vitro system, authors believe that further studies should be conducted to determine whether this form of NDDS has the same effects in vivo using animal studies.

\section{Conclusion}

The findings of this in vitro study have shown that the DSPEPEG2000 polymeric liposome is an effective nanocarrier of both a monoclonal antibody and a chemotherapy agent, and can be used to target chemotherapy to specific cells, in this case to CD20-positive B cells. Future developments in this form of targeted therapy will depend on the development of monoclonal antibodies that are specific for malignant cells, including antibodies that can distinguish between lymphoma cells and normal lymphocyte subsets.

\section{Acknowledgments}

This work was financially supported by the China Postdoctoral Science Foundation (2014M562605). The authors thank Ronggang Xi for his help with the cell culture and the preparation of sections for transmission electron microscopy.

\section{Disclosure}

The authors report no conflicts of interest in this work.

\section{References}

1. Sun J, Yang Q, Lu Z, et al. Distribution of lymphoid neoplasms in China: analysis of 4,638 cases according to the World Health Organization classification. Am J Clin Pathol. 2012;138(3):429-434.

2. Cheah CY, Fowler NH, Wang ML. Breakthrough therapies in B-cell non-Hodgkin lymphoma. Ann Oncol. 2016;27(5):778-787.

3. Judith J, Felix B, Susanne M, Hantel C, Süss R. Liposomal doxorubicin for active targeting: surface modification of the nanocarrier evaluated in vitro and in vivo challenges and prospects. Oncotarget. 2015;6(41):43698-43711.

4. Shetty RK, Adams BH, Tun HW, Runyan BR, Menke DM, Broderick $\mathrm{DF}$. Use of rituximab for periocular and intraocular mucosa-associated lymphoid tissue lymphoma. Ocul Immunol Inflamm. 2010;18(2): 110-122.

5. Esmaeli B, McLaughlin P, Pro B, et al. Prospective trial of targeted radioimmunotherapy with Y-90 ibritumomab tiuxetan (Zevalin) for front-line treatment of early-stage extranodal indolent ocular adnexal lymphoma. Ann Oncol. 2009;20(4):709-714.

6. Tan C, Waldmann TA. Proteasome inhibitor PS-341, a potential therapeutic agent for adult T-cell leukemia. Cancer Res. 2002;62(4):1083-1086.

7. Murawski N, Zwick C, Pfreundschuh M. Unresolved issues in diffuse large B-cell lymphomas. Expert Rev Anticancer Ther. 2010;10(3): 387-402.

8. Piktel E, Niemirowicz K, Wątek M, Wollny T, Deptuła P, Bucki R. Recent insights in nanotechnology-based drugs and formulations designed for effective anti-cancer therapy. J Nanobiotechnology. 2016; 14(1):39.

9. Bertrand N, Wu J, Xu XY, Kamaly N, Farokhzad OC. Cancer Nanotechnology: the impact of passive and active targeting in the era of modern cancer biology. Adv Drug Deliv Rev. 2014;66:2-25.

10. Stylianopoulos T, Jain RK. Design considerations for nanotherapeutics in oncology. Nanomedicine. 2015;11(8):1893-1890.

11. Yu M, Zheng J. Clearance Pathways and Tumor Targeting of Imaging Nanoparticles. ACS Nano. 2015;9(7):6655-6674.

12. Cerqueira BB, Lasham A, Shelling AN, Al-Kassas R. Nanoparticle therapeutics: technologies and methods for overcoming cancer. Eur J Pharm Biopharm. 2015;97(Pt A):140-151.

13. Fang J, Nakamura H, Maeda H. The EPR effect: unique features of tumor blood vessels for drug delivery, factors involved, and limitations and augmentation of the effect. Adv Drug Deliv Rev. 2011;63(3): $136-151$.

14. Taurin S, Nehoff H, Greish K. Anticancer nanomedicine and tumor vascular permeability: Where is the missing link? J Control Release. 2012;164(3):265-275.

15. Maeda H. Vascular permeability in cancer and infection as related to macromolecular drug delivery, with emphasis on the EPR effect for tumor-selective drug targeting. Proc Jpn Acad Ser B Phys Biol Sci. 2012; 88(3):53-71.

16. Yokota T, Saito T, Narushima Y, et al. Lympha-node staining with activated carbon CH40: a new method for axillary lymph-node dissection in breast cancer. Can J Surg. 2000;43(3):191-196.

17. Nakase $\mathrm{Y}$, Hagiwara A, Kin S, et al. Intratumoral administration of methotrexate bound to activated carbon partieles: antitumor effectiveness against human colon carcinoma xenografts and acute toxicity in mice. J Pharmacol Exp Ther. 2004;311(1):382-387.

18. Hagiwara A, Torii T, Sawai K, et al. Local injection of anti-cancer drugs bound to carbon particles for early gastric cancer - a pilot study. Hepatogastroenterology. 2000;47(32):575-578.

19. Zhong Y, Shuzheng M, Yingge Z. Using activated carbon nanoparticles to decrease the genotoxicity and teratogenicity of anticancer therapeutic agents. J Nanosci Nanotechnol. 2010;10(12):8603-8609.

20. Zhao B, Sun L, Zhang W, et al. Secretion of intestinal goblet cells: a novel excretion pathway of nanoparticles. Nanomedicine. 2014;10(4): 839-849.

21. Liu Zh, Robinson JT, Sun XM, Dai HJ. PEGylated nanographene oxide for delivery of water insoluble cancer drugs. $\mathrm{J} \mathrm{Am} \mathrm{Chem} \mathrm{Soc.} \mathrm{2008;}$ 130(33):10876-10877. 
22. Sahu A, Choi WI, Lee JH, Tae G. Graphene oxide mediated delivery of methylene blue for combined photodynamic and photothermal therapy. Biomaterials. 2013;34(26):6239-6248.

23. Shen $\mathrm{H}$, Zhang L, Liu M, Zhang Z. Biomedical applications of graphene. Theranostics. 2012;2(3):283-294.

24. Qu QL, Zhang YG, Sun L. Adsorption and sustained release of mitomycin C by activated carbon nano-particles. Bull Acad Mil Med Sci. 2004;28(6):551-552.

25. Qu QL, Zhang YG, Yang LZ, Sun L. Intraperitoneal chemotherapy with mitomycin $\mathrm{C}$ bound to activated carbon particles for nude mice bearing human gastric carcinoma. Chin J Oncol. 2006;28(4): 257-261.

26. Sun L, Zhang YG, Yang LZ. Observation of the lymph tissue-targeting property, retention in the intraperitoneal activated carbon nano-particles in mice. Bull Acad Mil Med Sci. 2005;29(4):349-351.

27. Yang LZ, Sun L, Zhang YG. Distribution, migration and excretion of bio-inert nano-particles in vivo. Lett Biotechnol. 2005;16(5): 525-527.

28. Zhang H, Sun L, Xiao E, Qu QL, Jiang S, Zhang YG. Intraperitoneal chemotherapy with mitomycin $\mathrm{C}$ bound to activated carbon nanoparticles using bioluminescence imaging technology. Mil Med Sci. 2011;35(4):299-303.

29. Yang LZ, Zhang YG. Pharmacokinetic study of intraperitoneal chemotherapy with mitomycin $\mathrm{C}$ absorbed to activated carbon particles in rats. J Cancer Prev Treat. 2008;15(20):1548-1551.
30. Mezzaroba N, Zorzet S, Secco E, et al. New potential therapeutic approach for the treatment of B-cell malignancies using chlorambucil/ hydroxychloroquine-loaded anti-CD20 nanoparticles. Plos One. 2013; 8(9): e74216.

31. Zhu X, Wu J, Shan W, et al. Polymeric nanoparticles a menable to simultaneous installation of exterior targeting and interior therapeutic proteins. Angew Chem Int Ed Engl. 2016;55(10):3309-3312.

32. Li Y, Yuan JN, Yang Q, et al. Immunoliposome co-delivery of bufalin and anti-CD40 antibody adjuvant induces synergetic therapeutic efficacy against melanoma. Int J Nanomed. 2014;9:5683-5700.

33. Yao HJ, Zhang YG, Sun L, Liu Y. The effect of hyaluronic acid functionalized carbon nanotubes loaded with salinomycin on gastric cancer stem cells. Biomaterials. 2015;35(33):9208-9223.

34. Yao HJ, Sun L, Liu Y, et al. Monodistearoylphosphatidylethanolaminehyaluronic acid functionalization of single-walled carbon nanotubes for targeting intracellular drug delivery to overcome multidrug resistance of cancer cells. Carbon. 2016;96:362-376.

35. Roskopf CC, Braciak TA, Fenn NC, et al. Dual-targeting triplebody 33-3-19 mediates selective lysis of biphenotypic CD19+ CD33+ leukemia cells. Oncotarget. 2016;7(16):22579-22589.

36. Ying X, Wen H, Lu WL, et al. Dual-targeting daunorubicin liposomes improve the therapeutic efficacy of brain glioma in animals. J Control Release. 2010;141(2):183-192.
International Journal of Nanomedicine

\section{Publish your work in this journal}

The International Journal of Nanomedicine is an international, peerreviewed journal focusing on the application of nanotechnology in diagnostics, therapeutics, and drug delivery systems throughout the biomedical field. This journal is indexed on PubMed Central, MedLine, CAS, SciSearch ${ }^{\circledR}$, Current Contents ${ }^{\circledR} /$ Clinical Medicine,

\section{Dovepress}

Journal Citation Reports/Science Edition, EMBase, Scopus and the Elsevier Bibliographic databases. The manuscript management system is completely online and includes a very quick and fair peer-review system, which is all easy to use. Visit http://www.dovepress.com/ testimonials.php to read real quotes from published authors. 